\title{
Pityriasis Versicolor in Kashmir - A Study of 200 Patients
}

\author{
Sheikh Manzoor and Yasmeen J Bhat \\ Department of Dermatology, STD and Leprosy, SKIMS Medical College Hospital, Srinagar.
}

\section{ABSTRACT}

Background: Pityriasis versicolor is a mild, superficial chronic infection of the skin characterised by discrete or confluent, scaly discoloured irregular macules on the upper trunk and extremities, caused by a commensal dimorphic fungus Malassezia. It is more common in tropical areas. The aim of present study was to find the epidemiology and clinical pattern of pityriasis versicolor in Kashmir, a temperate area.

Materials and Methods: Two hundred patients of pityriasis versicolor who attended the dermatology OPD at SKIMS Medical College were studied after confirming the diagnosis with $\mathrm{KOH}$ test. Most of the patients were male with a male-female ratio of 1.7:1, main age group involved was in second decade. Neck, chest and upper back were the main sites involved with patients presenting mainly with hypopigmented macules. The significant associated dermatological diseases were acne and seborrheic dermatitis. No significant association was seen with any systemic disorder.

Conclusion: The overall clinical course of pityriasis versicolor in Kashmir remains same as in tropical areas. J Med Sci 2010;13(1);4-6

Key words: Pityriasis versicolor, Mallasezia, Hypopigmented macules.

\section{Introduction}

Pityriasis versicolor is a mild, chronic infection of the skin characterisd by discrete or confluent, scaly discoloured irregular macules on the upper trunk and extremities. It is caused by a commensal yeast-Malassezia or pityrosporum orbiculare. ${ }^{1}$ Malassezia is a lipophilic dimorphic fungus comprising of seven different species. ${ }^{2}$ Under certain conditions like hot humid temperature, the commensal yeast transforms into mycelial pathogenic form. ${ }^{1,2}$ The fungi are usually present in the superficial layers of stratum corneum and on electron microscopy may

Reprint request:

Dr. Sheikh Manzoor

Assistant Professor

Department of Dermatology, STD and Leprosy

SKIMS Medical College, Srinagar

E-mail:yasmeen_bhat2001@yahoo.co.in be seen to invade not only between but within the keratinised cells. ${ }^{3}$ Clinically pityriasis versicolor can manifest as papulosquamous, folliculitis, inverse lesions, pityriasis versicolor rubra or erythrasmoid pityriasis versicolor. ${ }^{2}$ It is more common in tropical than in temperate zones. ${ }^{4,5}$ The disease is usually asymptomatic and patient seeks medical attention for cosmetic blemishes. Pityriasis versicolor may be associated with various systemic diseases like diabetes mellitus, cushing's disease, immunosuppressive conditions and cortico-steroid intake. ${ }^{6}$ Diagnosis of pityriasis versicolor can be established by Wood's lamp examination of lesions that show yellowish fluorescence and confirmed by microscopic visualisation of fungi after treating the skin scraping with $10 \% \mathrm{KOH}$. The short branched hyphae and spores show 'a spaghetti and meat balls' appea-rance. ${ }^{7} \mathrm{We}$ herewith describe the clinical spectrum of 200 patients of PV seen at SKIMS Medical College. 


\section{Material and Methods}

Two hundred randomly selected patients of pityriasis versicolor who attended the dermatology OPD of SKIMS Medical College from May 2006 to Jan 2008 were taken for study. Informed consent was taken from all the patients. A detailed history regarding age, sex, occupation, demography, socioeconomic status, any symptoms, duration, use of cosmetics and particular clothing was taken. Special emphasis was laid on history of recurrence, personal hygiene, climatic influence and family history. A thorough cutaneous examination was done for the site, distribution and colour of the lesions. Associated dermatological diseases were looked for. General physical and systemic examination of all the patients was done. Routine laboratory investigations were performed.

Diagnosis of pityriasis versicolor was confirmed by $\mathrm{KOH}$ test. Skin scraping from a scaly lesion was put on a glass slide and a drop or two of $10 \% \mathrm{KOH}$ solution run under the cover slip. After 5-10 minutes the mount was examined under microscope for the presence of short branched hyphae and spores. Culture was not attempted.

\section{Results}

Out of 200 patients of pityriasis versicolor, 126 (63\%)were male and $74(37 \%)$ female with a male female ratio of 1.7:1. Most of the patients were young adults with majority (40.5\%) in 11-20 yr age group with only 2 patients below 10 years and 6 patients above 50 years (Table 1 ).

\begin{tabular}{|lc}
\hline Table 1: Age distribution of patients with Pityriasis versicolor & \\
\hline Age (years) & No. of patients \\
\hline $1-10$ & 2 \\
\hline $11-20$ & 81 \\
\hline $21-30$ & 64 \\
$31-40$ & 30 \\
\hline $41-50$ & 17 \\
\hline $51-60$ & 6 \\
\hline
\end{tabular}

Majority of patients in our study were students followed by labourers and housewives (Table 2).

In our study, 110 patients belonged to lower, 74 to middle and 16 to higher socioeconomic class. Demography showed $146(73 \%)$ patients belonging to rural and $54(27 \%)$ to urban. Duration of disease varied from 5 days to 2 years with a mean age of 2 months. Past history of pityriasis versicolor was given by $90(45 \%)$ patients and $36(18 \%)$ had positive family history. Most of the patients (62\%) were asymptomatic where as $31 \%$ had mild and $7 \%$ moderate pruritus. None of our patients attributed the onset of lesions to the use of cosmetics or particular clothing. Neck, chest and upper back involvement was seen in $101(50.5 \%)$ patients. In $17.5 \%$ neck alone and in
Table 2: Occupation of patients with Pityriasis versicolor

\begin{tabular}{lc}
\hline Occupation & No. of patients \\
\hline Students & 63 \\
\hline Labourers & 37 \\
\hline Housewives & 32 \\
\hline Farmers & 28 \\
\hline Employees & 27 \\
\hline Businessmen & 13 \\
\hline
\end{tabular}

$22.5 \%$ chest alone was involved. Involvement of flexures was seen in $8(4 \%)$, face in $6(3 \%)$ and abdomen in $5(2.5 \%)$ patients. Morphologically, most (67\%) of the lesions were hypopigmented macules, followed by hyperpigmented $(28 \%)$ and mixed in 5\% (Figure 1). Branny scaling was present in $82.5 \%$ of patients. Other dermatological disorders seen included acne vulgaris in $20(10 \%)$, seborrheic dermatitis in $15(7.5 \%)$, vitiligo in 4 and alopecia areata in 3 patients. Majority of the patients had lesions in summer (46\%), followed by spring (24.5\%), autumn $(18.5 \%)$ and winter (11\%). Eighteen patients were hospitalised for some underlying systemic disease like diabetes mellitus or surgical complaint, 7 patients were on immunosuppressant drugs or systemic corticosteroids, and were referred to dermatology for pityriasis versicolor.

\section{Discussion}

Pityriasis versicolor is a common dermatological disorder due to chronic infection of skin by the fungus Mallasezia, characterised by discrete or confluent discoloured macules mainly on the upper trunk. It is more common in tropical areas. The study was done to find the epidemiology and clinical pattern of pityriasis versicolor in Kashmir, a temperate area. Males and females are equally prone to develop it. ${ }^{4}$ Our study showed a male

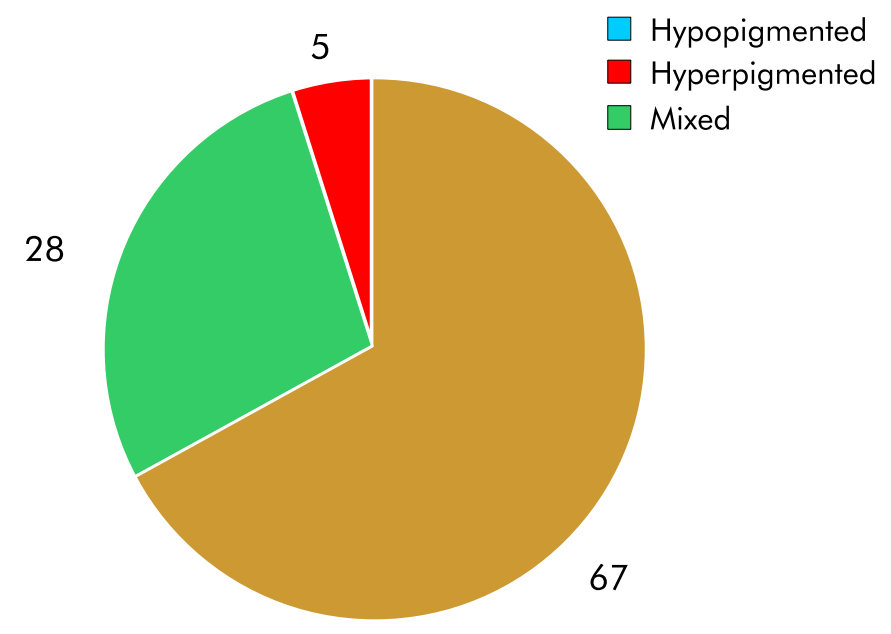

Figure 1: Percentage of discoloured macules in Pityriasis versicolor patients 
predominance (male-female ratio of 1.7:1) that may be due to outdoor work by males leading to more perspiration. The most affected age group was 11-20 years followed by 21-30 years, showing results similar to other studies. ${ }^{4,5}$ This may be due to increased growth of commensal Mallasezia in this age group. Since young adults are commonly involved, students were the most affected ones in our study. Majority (55\%) of our patients belonged to lower socioeconomic class and $73 \%$ had rural background that may be due to poor personal hygiene. Pityriasis versicolor is usually asymptomatic ${ }^{8,9}$ which was a feature in most of our patients $(62 \%)$ with mild to moderate pruritus in the rest. Patients of pityriasis versicolor usually have recurrence of lesions and about $25 \%$ have family history of similar lesions. ${ }^{10}$ In our study, $45 \%$ patients had past history of pityriasis versicolor but only $18 \%$ had positive family history. Pityriasis versicolor shows a seasonal variation with most of the cases occurring from July to September. ${ }^{4,5}$ Majority of our patients also presented in the months of May to September. Most common sites involved in pityriasis versicolor are neck, chest, upper arms and abdomen. Although cases have been reported where other unusual sites like scalp, popliteal fossa, genitalia and groin were involved, ${ }^{11}$ we noticed neck and chest involvement in most patients. Face involvement has been reported as rare, ${ }^{12}$ but we noticed it in 6 patients. Pityriasis versicolor mainly presents as hypopigmented macules, followed by mixed hypo and hyperpigmented lesions. ${ }^{4}$ Our patients also had hypopigmented macules in $67 \%$, followed by hyperpigmented (28\%) and only $5 \%$ had mixed lesions. This difference may be due to the fair complexion of our patients where lesions are mainly hyperpigmented. Seborrheic dermatitis has been associated with pityriasis versicolor in about $10-15 \%$ of patients. ${ }^{4,5}$ Our study showed seborrheic dermatitis in $7.5 \%$ and acne in $10 \%$ of patients. Antibodies against pityrosporum are raised whereas $\mathrm{T}$ and $\mathrm{B}$ lymhocytes are within normal range in pityriasis versicolor. $^{13,14}$ Mean plasma cortisol level is raised in patients with pityriasis versicolor. ${ }^{6}$ Systemic diseases like diabetes mellitus were seen in few of our patients but were not significantly associated.

Kashmir is a cold place and we see cases of pityriasis versicolor mostly in summer months i.e from May to
September with a rapid decline as the temperature falls but the clinical course remains the same as in other hot places.

\section{References}

1. Gupta AK, Bluhm R, Summerbell R. Pityriasis versicolor. $\mathcal{F}$ Eur Acad Dermatol Venereol. 2002;16:19-3.

2. Hay RJ, Moore MK. Mycology. In: Burns T, Breathnach S, Cox N, Griffiths C, editors.Rook's Textbook of Dermatology.6th edn.Oxford: Blackwell Science; 2004. p.31.1-101.

3. Lee KH, Kim YG, Bang D, Kim YA.Scanning electron microscopy of Malassezia furfur in tinea versicolor. Yonsei Med J. 1989;30:334-8.

4. Rao GS, Kuruvilla M, Kumar P, Vinod V. Clinico Epidemiological studies on tinea versicolor. Indian $\mathcal{F}$ Dermatol Venereol Leprol. 2002;68:208-9.

5. Dutta S, Bajaj AK, Basu S, Dikshit A. Pityriasis versicolor: socioeconomic and clinicomycological study in India. Int 7 Dermatol.2002;41:823-4

6. Kumar B, Kaur I, Saily R, Kaur S, Dash RJ. Elevated levels of plasma cortisol in Pityriasis Versicolor. Indian f Dermatol Venereol Leprol. 1985;51:205-207

7. Gupta AK, Batra R, Bluhm R, Faergemann J. Pityriasis Versicolor. Dermatol Clin. 2003;21:413-29.

8. Abdul Razack EM, Thambiah AS. A clinical study of pityriasis versicolor in Madras. Sabouraudia 1977; 15:30511

9. Ingordo V, Naldi L, Colcchia B, Licci N. Prevalence of pityriasis versicolor in young Italian sailors. BrF Dermatol. 2003;149:1270-2.

10. Hafez M, el-Shamy S. Genetic susceptibility in pityriasis versicolor. Dermatologica 1985;171:86-8.

11. Kamalam A, Thambiah AS. A study of 3891 cases of mycosis in the tropics. Sabouraudia 1976;14:129-148

12. Blumenthal HL. Tinea versicolor. Arch Dermatol. 1971;103:461-2.

13. Sohnle RG, Collisis LC. Relative antigenicity of Pityrosporum orbiculare and Candida albicans. 7 Invest Dermatol. 1980;75:279-83.

14. Mittal RR, Singh P, Prasad D. Immunological study of Pityriasis versicolor and Pityrosporum folliculitis. Indian $\mathcal{F}$ Dermatol Venereol Leprol. 1992;58:260-1. 